\title{
Erinnerung und Auftrag
}

Othmar Kehl

Korrespondenz:

Dr. med. Othmar Kehl

Chefarzt Medizin

Heiden AA Spital

Werdstrasse 1

CH-9410 Heiden
Als eine Schweizer Delegation an einem strahlend schönen 13. Oktober 2009 in Nagasaki vor dem Universitätsspital die «Nagasaki Peace Bell» mit viel Medienpräsenz für das Henry-Dunant-Museum Heiden entgegennehmen durfte, dachte niemand an die Bedeutung, die diese Glocke durch den 11. März 2011 zusätzlich bekommen würde. Auch nicht während des Jahres 2010, als die Friedensglocke in der Eingangshalle des «neuen Spitals» Heiden aufgestellt war. Die Glocke ist eine Replika der nach dem Atombombenabwurf vom 9. August 1945 in Nagasaki unversehrt gebliebenen Angelus-Glocke. Sie wurde dem Henry-Dunant-Museum geschenkt zu Ehren von Henry Dunant, der den Friedensnobelpreis im «alten Spital» von Heiden erhielt, in dem er 18 Jahre später am 30. Oktober 1911 verstarb.

Im Bewusstsein der Bedeutung dieses Geschenks wurde sorgfältig der definitive Standort auf dem Spitalgelände vor dem Dunant-Haus ausgewählt. Den definitiven Glockenträger erstellte die Künstlerin Lucie Schenker aus St. Gallen. Eine würdige Einweihungsfeier und ein medizinisches Symposium zum Thema «Gesundheitsschäden nach Strahlenexposition aufgrund der Erfahrungen in Hiroshima, Nagasaki und Tschernobyl» wurden minutiös vorbereitet. Als Hauptredner war der japanische Experte Professor

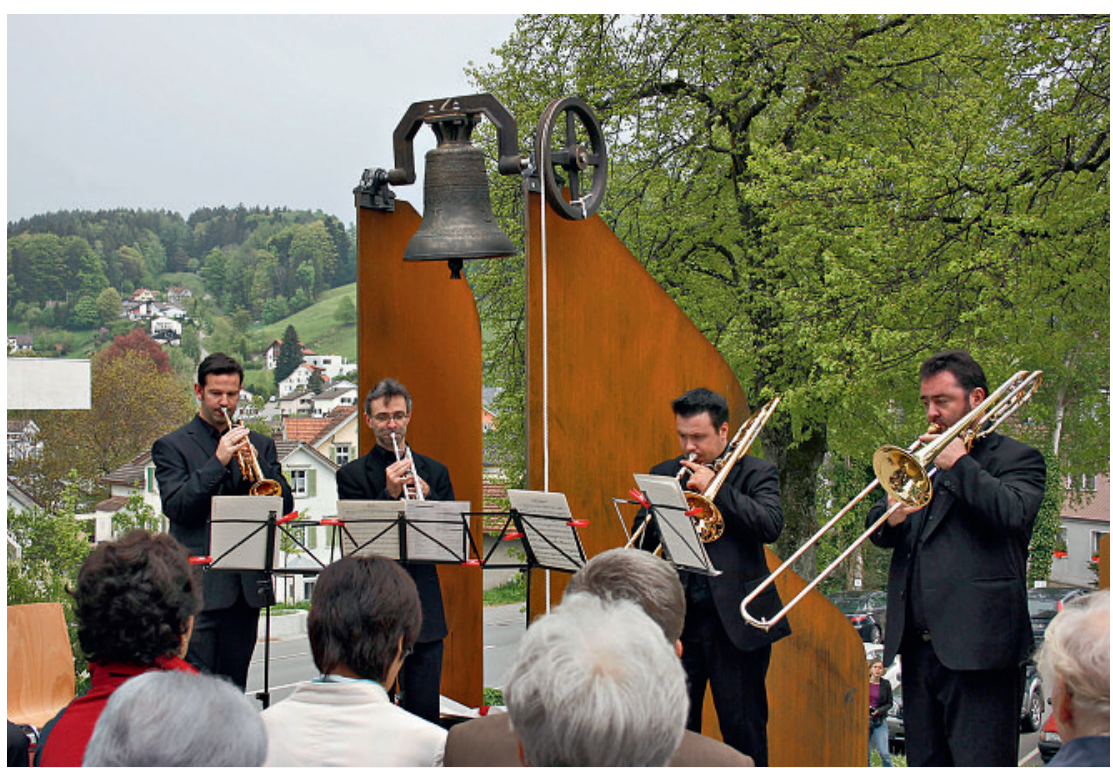

Mit einer feierlichen Eröffnung wurde die Replika der nach dem Atombombenabwurf in Nagasaki unversehrt gebliebenen Angelus-Glocke vor dem Henry-Dunant-Museum aufgestellt.
Dr. med. Shunichi Yamashita, Leiter des «Atomic Bomb Disease Institutes» in der Hochschule für biomedizinische Wissenschaften in Nagasaki, eingeladen.

Doch dann kam der 11. März 2011 mit dem schweren Reaktorunfall in Fukushima. Alles bekam plötzlich eine andere Bedeutung: die Feier vom 30. April 2011 wurde zum eindrücklichen und stimmungsvollen Gedenken an die Opfer von Fukushima, aber auch zur überzeugenden Manifestation gegen den atomaren Wahnsinn. Das medizinische Symposium musste wegen der Einberufung des Hauptreferenten als Berater der japanischen Regierung abgesagt werden.

«Doch dann kam der 11. März 2011 mit dem schweren Reaktorunfall in Fukushima. Alles bekam plötzlich eine andere Bedleutung.»

Die Friedensglocke aber ruht «auf zwei dünnen Metallmembranen, welche wellenförmig in die Landschaft ausgreifen. Die Zerbrechlichkeit des Friedens wird symbolisiert durch die dünnen Wellen. Die Verletzlichkeit der Glocke und deren Botschaft wird sichtbar gemacht durch das blosse Auflagern der Achse auf den Eisenteilen. Die Form der Skulptur verleiht der Glocke Geborgenheit und legt sich schützend um den Klangkörper zur Verkündung des Friedens». So formulierte es Lucie Schenker in ihrer Grussbotschaft.

Der Respekt, welcher der Nagasaki-Friedensglocke entgegengebracht wird, zeigte sich in der musikalischen Darbietung des über 60 Jahre alten japanischen Volksliedes «Nagasaki no kane». In der Festansprache unterstrich Regierungsrat Dr. Matthias Weishaupt, Gesundheitsdirektor von Appenzell Ausserrhoden, dass «mit der Friedensglocke von Nagasaki beim Henry-Dunant-Museum auch wir ein aktiver Teil der weltumspannenden Erinnerungsgesellschaft werden. (...) Mit der Einweihung der Glocke in Heiden wird auch für uns der Kampf für die nukleare Abrüstung und gegen den atomaren Wahnsinn zur moralischen, sozialen und politischen Pflicht. Gemeinsam engagieren wir uns für den Frieden auf unserer Erde.» 